\title{
ESTADO EMPÁTICO Y CIUDADANÍA PRECARIA - REFLEXIONES EN TORNO AL CASO EMBLEMÁTICO DE BELLAVISTA (BOJAYÁ - COLOMBIA) ${ }^{1}$
}

\author{
EMPATHIC STATE AND PRECARIOUS CITIZENSHIP - REFLECTIONS \\ ON THE EMBLEMATIC CASE OF BELLAVISTA (BOJAYÁ - COLOMBIA)
}

\author{
Lina Buchely \\ Universidad Icesi - Cali (Colombia)
}

Recebimento: 18 fev. 2017

Aceitação: 4 maio 2017

\begin{abstract}
Como citar este artigo / How to cite this article (informe a data atual de acesso / inform the current date of access):
BUCHELY, Lina. Estado empático y ciudadanía precaria - Reflexiones en torno al caso emblemático de Bellavista (Bojayá - Colombia). Revista da Faculdade de Direito UFPR, Curitiba, PR, Brasil, v. 62, n. 1, jan./abr. 2017, p. 211 230. ISSN 2236-7284. Disponível em: <http://revistas.ufpr.br/direito/article/view/50742>. Acesso em: 30 abr. 2017. DOI: http://dx.doi.org/10.5380/rfdufpr.v62i1.50742.
\end{abstract}

\section{RESUMEN}

Este texto recoge la experiencia del trabajo en Bellavista, Bojayá (pacífico colombiano) articulando tres elementos: el carácter emocional de las manifestaciones oficiales que se construyen en escenarios de conflicto; la ciudadanía precaria que construyen las víctimas de violencia política inmersas actualmente en procesos de construcción de memoria histórica, perdón, duelo y reparación; finalmente, la fragmentación y ambigüedad que representan esos escenarios de discusión para el estado colombiano, en el proceso de posconflicto. Los resultados son expuestos a través de ejercicios etnográficos que recogen parte del trabajo de campo, desarrollado durante todo el año 2016.

\section{PALABRAS CLAVE}

Antropología del Estado. Ciudadanía precaria. Pacífico colombiano. Bojayá.

\begin{abstract}
This text reflects the experience of the work in Bellavista, Bojayá (Pacific Colombian) articulating three elements: the emotional character of the official demonstrations that are built in conflict scenarios; The precarious citizenship that the victims of political violence construct currently immersed in processes of construction of historical memory, forgiveness, mourning and reparation; Finally, the fragmentation and ambiguity that represent these scenarios of discussion for the Colombian state, in the process of postconflict. The results are presented through ethnographic exercises that collect part of the field work, developed throughout the year 2016.
\end{abstract}

\section{KEYWORDS}

Anthropology of the State. Precarious citizenship. Pacific Studies. Bojayá - Colombia.

\footnotetext{
${ }^{1}$ Este documento se basa en mi trabajo de campo como investigadora del proyecto Políticas del perdón y el retorno: Bojayá, 15 años después. Este es un proyecto conjunto de la Universidad Icesi, institución donde laboro, y el Centro Nacional de Memoria Histórica. Sin embargo, las reflexiones personales que le dan origen y sustento a este artículo no comprometen ni representan a ninguna de las dos instituciones.
} 


\section{INTRODUCCIÓN}

Llegamos tarde a la reunión. Las personas que nos esperaban estaban en la casa parroquial de Bellavista nuevo y no en Bellavista viejo, lugar donde había ocurrido la masacre el 2 de mayo, hace 14 años. Cuando entramos, un líder del Comité de Víctimas del Dos de Mayo (CVDM) estaba hablando. Él había estado con nosotros en Cali hacía dos semanas en un evento del Centro de Estudios Afrodiaspóricos, y a él le debíamos poder asistir a la asamblea sobre el Cristo Negro de Bojayá.

Sentados había, más o menos, 50 personas. Había representantes de todas las comunidades: Bellavista, Pogue, Tanguí, Puertoconto, Tadó, entre otras. El líder del CVDM hablaba de la dificultad de sacar al Cristo Negro de La Habana, de la cantidad de trámites y papeles para conseguirlo, de que había tocado mutilar sus brazos de dos metros de altura para que fuera posible traerlo en el avión. Todos y todas escuchaban atentos.

El municipio de Bojayá está ubicado en el Atrato medio, área rural dispersa. Para llegar ahí se necesita un transporte fluvial entre Quibdó y Bellavista, que dura entre tres y cinco horas y cuesta ochenta mil pesos en su valor comercial (pagados a pangueros ${ }^{2}$ en la orilla del Atrato en Quibdó, cerca de la catedral). Según el último censo de población realizado en 2005 por el Departamento Administrativo Nacional de Estadística (Dane), tiene 9941 habitantes: 58 \% son afrocolombianos y $41 \%$ indígenas. El 95 \% no ha cubierto sus necesidades básicas desde $1993^{3}$. En Bellavista, su cabecera municipal, existe solo un puesto de salud, no un hospital. Las personas que no residen allí deben acceder a los servicios de salud por vía fluvial. En ese contexto, el 19 de septiembre de 2016, el Comité de Víctimas del Dos de Mayo (CVDM) convocó a una reunión para discutir la aceptación o no del “Cristo Negro de Bojayá” que entregó las FARC-EP a la comunidad.

Bojayá es un caso emblemático del conflicto armado interno por los hechos ocurridos el 2 de mayo de 2002. Ese día, en combates entre el Frente 58 de las FARC-EP y el Bloque Élmer Cárdenas de las Autodefensas Unidas de Colombia (AUC), murieron más de 80 personas que se resguardaban en la parroquia de Bellavista, la cabecera municipal. Después de catorce años de la masacre, la Fiscalía no ha terminado con éxito el proceso de identificación de los cuerpos. Los duelos y ritos mortuorios de las víctimas no han podido realizarse. Según el informe del Centro Nacional de Memoria Histórica ${ }^{4}, 126$ personas aún tienen esquirlas en sus cuerpos y afectaciones en su salud derivadas del ataque. En su mayoría, la población afectada no ha recibido la atención médica y psicológica necesaria. Ocho personas han muerto después de la masacre con diagnóstico de cáncer,

\footnotetext{
${ }^{2}$ Las "pangas" son lanchas a motor que transitan por el río Atrato. Como "pangueros" se conoce a los conductores de estas lanchas.

${ }^{3}$ VERGARA-FIGUEROA, A. (2016) ¿Cómo puede Bojayá perdonar? Recuperado de <https://goo.gl/Dc1tkI> el 6 de octubre de 2016.

${ }^{4}$ CENTRO NACIONAL DE MEMORIA HISTÓRICA - CNMH (2010) Bojayá: La guerra sin límites. Bogotá: Taurus.
} 
patología que para la comunidad está asociada de manera directa con el estallido de la pipeta ese 2 de mayo.

Bojayá también se ha convertido en un ícono del perdón. Los resultados de sus votaciones frente al plebiscito sorprendieron al mundo entero. Más de 90 \% de la población que participó -que no es mucha dada la precariedad de los puestos de votación y la exclusión de la comunidad indígena de estos procesos- votó positivamente para respaldar los Acuerdos de La Habana. Su experiencia como comunidad, además, ha tenido gran exposición mediática. En la ceremonia de firma del acuerdo final, el 26 de septiembre en Cartagena, mujeres de Pogue cantaron un $a l a b a o^{5}$, imagen que se volvió rápidamente tendencia en las redes sociales. Sus voces decían:

$$
\begin{gathered}
\text { Nos violaron el derecho, } \\
\text { en nuestra comunidad, } \\
\text { ni a la pesca ni al trabajo } \\
\text { nos dejaban llegar. } \\
\text { Queremos justicia y paz } \\
\text { que venga de corazón, } \\
\text { pa' que llegue a nuestros campos, } \\
\text { salud, paz y educación } 6 \text {. }
\end{gathered}
$$

Desde enero de 2016, la Universidad Icesi, como parte del Grupo Regional de Memoria Histórica, y el CNMH han venido trabajando de manera conjunta en el municipio, en el marco del proyecto “Políticas del perdón y el retorno: Bojayá, 15 años después”. Este proyecto, liderado por un equipo multidisciplinario compuesto por varios docentes de la Universidad interesados en temas relacionados con la construcción de memoria, el enfoque étnico y la perspectiva de género, da continuidad a un proceso extenso que el Centro ha desarrollado en la zona con las víctimas de la masacre del 2 de mayo de 2002.

Este documento se basa en mi trabajo como investigadora vinculada al Grupo Regional de Memoria y especialmente en la reconstrucción de esta experiencia a la luz de la lectura de las emociones y la política que ofrece la antropología del estado ${ }^{7}$. Usé técnicas etnográficas como la

\footnotetext{
${ }^{5}$ Los alabaos son cantos no musicalizados que cuentan historias de dolor con voces desgarradoras y hacen parte de los ritos mortuorios de la comunidad de Bojayá. Su potencia y su belleza han sido admiradas y documentadas por universidades colombianas y extranjeras. Sobre los alabados de Pogue, véase: El oficio de cantar la memoria - Las musas de Pogue, que recoge las canciones del Grupo de Cantadoras de Pogue, Bojayá (Chocó-Colombia), publicado por la Universidad de British Columbia y el CNMH, y la cartilla Pogue: un pueblo, una familia, un río. Historias contadas por la comunidad de Pogue, publicada con el apoyo de USAID, OIM y CNMH.

${ }^{6}$ VERGARA-FIGUEROA, A. (2016) ¿Cómo puede Bojayá perdonar? Recuperado de <https://goo.gl/Dc1tkI> el 6 de octubre de 2016.

${ }^{7}$ LASZCZKOWSKI, M. y REEVES, M. (2015) Affective states - entanglements, suspensions, suspicions. Social Analysis, 59(4), pp. 1-14.
} 
observación participante y las entrevistas para documentar los hallazgos que analizo. Realicé las observaciones durante mis visitas a las comunidades de Bojayá (en su mayoría, a Bellavista, aunque también registro otras a Pogue y La Loma), las reuniones del CNMH en Bojayá y Bogotá, las sesiones de trabajo a la Unidad de Víctimas de Quibdó, los encuentros con el CVDM y en eventos relacionados con el proceso de aprobación de los Acuerdos de La Habana y el posterior reconocimiento al presidente Santos con el Nobel de Paz, hechos sucedidos entre enero y noviembre de 2016. También recurro a las entrevistas con un miembro del CVDM y las conversaciones con varios funcionarios del CNMH. En general, sigo la metodología de acción sin daño desarrollada por el Centro Nacional de Memoria Histórica para hacer las intervenciones en las comunidades.

Cada sección del texto comienza con viñetas etnográficas basadas en las notas de campo de mi tercera visita a Bojayá, entre el 19 y el 22 de septiembre de 2016. Estas notas reconstruyen lo sucedido alrededor del Cristo Negro de Bojayá como mecanismo de reparación simbólica ofrecido por las FARC-EP a la comunidad. Esta experiencia condensa de manera especial los tres aspectos centrales de mi análisis: 1) el carácter emocional de las manifestaciones oficiales desarrolladas en escenarios de conflicto; 2) la ciudadanía precaria que construyen las víctimas de violencia política inmersas actualmente en procesos de construcción de memoria histórica: perdón, duelo y reparación; 3) la fragmentación y ambigüedad que representan esos escenarios de discusión para el estado colombiano en el proceso de posconflicto ${ }^{8}$.

\section{BELLAVISTA Y LAS BUROCRACIAS “BLANDAS”}

La primera mujer en hablar, tras darle la palabra a la comunidad, era conocida. DC, como le decían, es una vecina muy cercana del Barrio Bellaluz. En su intervención, propuso varios puntos importantes. El primero de ellos era que el Cristo era visto como una imposición de las FARC a la comunidad. ¿Cómo era posible que no se les hubiera ni siquiera preguntado antes de elaborarlo? ¿Por qué no se les había preguntado si se sentían cómodos con ese mecanismo de "reparación simbólica”, como lo llamaba la guerrilla? ¿Por qué justamente un cristo, el objeto de su fe? En el segundo punto, DC resaltó la importancia del cristo original de la iglesia de Bellavista: mutilado, sobrevivió a la masacre, y quizá por esto cuenta con especial devoción. Ya Bellavista tenía su cristo y no necesitaba otro. Estaba bien si otra comunidad quería el Cristo, pero, para DC, Bellavista no lo necesitaba, o al menos eso se había discutido en reuniones previas entre los vecinos.

Después habló un hombre de Pogue, NA. Su posición era completamente distinta. Hablaba del perdón y de la paz, y de lo importante que sería aceptar el Cristo como un símbolo que ayudaría en la coyuntura de la firma de los Acuerdos de La Habana. Insistía en que el Cristo debía de estar en Bellavista, como "epicentro" de la masacre.

\footnotetext{
${ }^{8}$ Las viñetas etnográficas fueron seleccionadas por su relación con aspectos teóricos que deseo resaltar en el texto: la existencia de una ciudadanía por frustasión (que no por dignidad y participación, como lo enseña el mito liberal) y el carácter negociado (y político) del perdón y la memoria. El texto de las viñetas hace parte de una sola narración y ha sido fragmentado para la construcción de este texto.
} 
Mi trabajo anterior ha estado relacionado con la manera en que la antropología del estado se pregunta por las manifestaciones físicas del estado, cómo las documenta y las estudia. Esa experiencia, aunada a mi entrenamiento disciplinar como abogada, me ha dejado la obsesión de relatar las presencias del estado. En Bojayá, el ejercicio ha sido difícil. Hay una presencia notable del Ejército. Existen unas pocas oficinas de entidades promotoras de salud y de empresas prestadoras de servicios públicos, una registraduría, algunos jardines de primera infancia del Instituto Colombiano de Bienestar Familiar, entre otros.

Sin embargo, pese a lo emblemático del caso y la "feria de chalecos" de instituciones internacionales, universidades y organizaciones no gubernamentales que han visitado la zona, interesadas en documentar sus procesos, es evidente que Bojayá está olvidada por las que llamo las “burocracias duras” del estado, es decir, por las entidades con competencias centrales en la asignación de presupuestos (Presidencia, ministerios, departamentos administrativos). Allí los representantes estatales son personas vinculadas al Centro Nacional de Memoria Histórica (CNMH) y a la Unidad de Víctimas, ambas adscritas al Departamento para la Prosperidad Social (DPS), con vigencias temporales a partir de la Ley 1448 de 2011 y presupuestos exiguos. Estas burocracias "blandas” no tienen oficinas permanentes en el territorio. Van ocasionalmente a acompañar procesos específicos, siempre relacionados con lo que aquí llamaré gestiones emocionales: construcción de memoria, elaboraciones de duelo, propuestas de perdón.

Según mis observaciones, la comunidad de Bojayá está politizada, tiene fuertes procesos de participación y empoderamiento. En mis pocas visitas, presencié al menos tres reuniones generales en las que se discutían asuntos de interés colectivo con representantes de todas las comunidades. Sin excepción, esos asuntos estaban relacionados con la masacre, su reconocimiento como víctimas y los procesos de reparación que el estado había previsto para ellos y ellas.

Un elemento que me llamó la atención en las visitas fue la manera en que la identidad de víctima tiene expresiones cotidianas poderosas. En el momento de su expedición, la Ley 1448 de 2011 generó muchas discusiones en torno a la etiqueta utilizada legalmente para nombrar a los afectados, sobrevivientes, desplazados o víctimas del conflicto armado ${ }^{9}$. Cada etiqueta traía unas implicaciones profundas. Se les llamó víctimas, y ser víctimas, en el estado actual del posconflicto y me refiero a sus efectos cotidianos más básicos, relacionados con los trámites y las acciones de las personas afectadas en su vida diaria- significa poseer un lugar de enunciación caracterizado por dos

\footnotetext{
${ }^{9}$ LEMAITRE RIPOLL, J. (2013) Diálogo sin debate: la participación en los decretos de la Ley de Víctimas. Revista de Derecho Público, 31, pp. 5-37.
} 
elementos: a) ser beneficiario especial y prioritario (discursivamente) de prestaciones públicas encaminadas a la reparación integral; b) tener algo que la literatura ha denominado "superioridad moral” en las transacciones con las burocracias públicas ${ }^{10}$.

Pese a que me incomoda su nombre, después de haber compartido con los mal llamados “superiores morales” (y me gustaría enfatizar en la crueldad del enunciado), esta etiqueta remite a una especie de principio de no cuestionamiento, condescendencia y privilegio de las víctimas. En efecto, y concentrados en el mundo de los intercambios burocráticos, este elemento remite a actuaciones concretas como la inversión de la carga de la prueba, el seguimiento de protocolos especiales y el principio de no victimización secundaria en los procesos de interacción con los empleados públicos ${ }^{11}$.

Es fascinante ver cómo esta característica de la literatura no es reconocible, por ejemplo, por quienes empiezan sus procesos de reclamación en Cali. En lugares como las Unidades de Atención y Orientación (UAO) a población desplazada, las víctimas del conflicto no hablan de un "privilegio" frente a las burocracias públicas, sino de maltrato e indignidad derivados de su situación ${ }^{12}$.

Ahora bien, lo que llamo “ciudadanía precaria” surge de las construcciones anteriores. La gestión emocional del estado construye los discursos de protección de las víctimas como un elemento central para su interacción. Esos guiones son empoderadores y detonantes de procesos comunitarios exitosos en la experiencia, por ejemplo, de Bojayá. Sin embargo, ese reconocimiento precariza las formas en las que los ciudadanos y ciudadanas se relacionan con el estado y hacen sus exigencias. Mientras el tema "emocional” conduce sus interacciones, las discusiones materiales sobre la ciudadanía social ${ }^{13}$ son anuladas.

\footnotetext{
10 RESTREPO, E. (2010) Cómo garantizar justica a los desplazados. El desplazado como paria. La garantía de los derechos a la verdad, la justicia y la reparación de las víctimas del delito de desplazamiento forzado en Colombia. En: Más Allá Del Desplazamiento. Bogotá: Editorial Uniandes.

${ }^{11}$ ALVIAR GARCÍA, H. y JARAMILLO SIERRA, I. C. (2012) Feminismo y crítica jurídica: el análisis distributivo como alternativa crítica al legalismo liberal. Bogotá: Siglo del Hombre-Uniandes.

${ }^{12}$ La Ley 1448 de 2011 dispone el diseño de un andamiaje institucional para atender y reparar a las víctimas del conflicto armado, que se fundamenta en las estructuras burocráticas creadas por las leyes anteriores: los sistemas de atención para población desplazada (Ley 387 de 1997), para población de víctimas (Ley 418 de 1997) y la estrategia de reparación individual por vía administrativa del Decreto 1290 de 2008. Las Unidades de Atención y Orientación (UAO) son parte de la infraestructura nacional y local consolidada mediante la Ley 387 de 1997, específicamente las ubicadas en los municipios y los programas de asistencia en vivienda y líneas de crédito de la Ley 418 de 1997. Ver: RECALDE, G. "En lo que esté a mi alcance les ayudo”. Los funcionarios de base y las víctimas en el proceso de declaración para la inscripción en el Registro Único de Víctimas del conflicto armado. En: JARAMILLO, I. C. y BUCHELY, L. (Coord.). Etnografías burocráticas. Bogotá: Uniandes (en proceso de edición).

${ }^{13}$ Bajo la etiqueta del bienestar se organizan las transacciones típicas de la política social, entendidas como unas prestaciones obligatorias del estado hacia los ciudadanos dentro de un esquema de ciudadanía social (MARSHALL, 1992). Según esta visión de los estados liberales, la ciudadanía social entra a completar los derechos civiles y políticos con la preocupación por la igualdad material. Esa preocupación por "lo social” fue incorporada en las constituciones de
} 


\section{EL ESTADO EMPÁTICO: GESTIÓN EMOCIONAL Y ESTRATEGIAS DE DUELO}

Dos mujeres de Bellavista lo siguieron en las intervenciones. La primera se refirió a la imposición y la violencia del gesto. Era una imposición que se les dijera cómo perdonar, con qué perdonar y qué regalos aceptar. Era ofensivo, además, que el gesto incluyera un objeto de fe. Esto era una burla, una mofa. La segunda mujer habló del dolor que le generaría ver al cristo que les enviaban las FARC en el lugar desde donde se había disparado la pipeta. Mencionó las esquirlas que tenía en su pierna izquierda, los calambres que no la dejaban dormir por la noche, la injusticia del gesto. Además, los victimarios decidían cómo repararlos, y no ellos. Ella necesitaba atención médica, no un cristo. Necesitaba un mejor centro de salud, una casa habitable. Necesitaba una reparación material.

Después de esa intervención, el ánimo se calentó. Varias de las mujeres le decían al único hombre que manifestó estar abierto a la recepción del cristo que les fuera a llevar "razones" a los guerrilleros. Esto lo molestó y empezó a desacreditar esas opiniones. Era evidente que las fronteras entre víctimas y victimarios no eran claras ahí.

Las emociones están en el centro de las discusiones en torno al estado. En la teoría hobbesiana del contractualismo, por ejemplo, el Leviatán surge para controlar el temor de las personas a morir en una situación de amenaza de todos contra todos. Entendido de esta manera, el estado es la respuesta al miedo ${ }^{14}$. Por el contrario, en las teorías críticas, ese miedo no se instala de manera individual. El individuo no es una unidad de transacción política; por el contario, solo la relación con sus semejantes le permite reconocer relaciones sistemáticamente asimétricas ${ }^{15}$.

En las teorías contemporáneas, autores como Partha Chatterjee explican cómo sentimientos de frustración y desconsuelo construyen los cuerpos de las sociedades actuales. El proyecto liberal de estado no coincide con la realidad de la mayoría de ciudadanos del mundo (dada la vastedad del mal llamado “tercer mundo”) y la política se convierte en una suerte de atención paliativa para mermar la desilusión del proyecto político no alcanzado. Ser ciudadanos en el tercer mundo nos enseña que nuestra experiencia política se relaciona más con esa frustración frente a lo incumplido que con la satisfacción por lo alcanzado ${ }^{16}$.

En ese contexto, se ha visibilizado recientemente la idea de incluir el afecto en la vida política. Esa discusión considera al estado como un sujeto social en la vida cotidiana, atendiendo a la experiencia subjetiva del poder del estado (en la vida de las personas) y a las técnicas, intensidades y mecanismos por los cuales se reproduce todos los días como forma de gobierno y disciplina. Desde

\footnotetext{
los países latinoamericanos con la etiqueta de los derechos económicos sociales y culturales (DESC) Ver: ESPINGANDERSEN, G. (1999) Social foundations of postindustrial economies. Oxford, NY: Oxford University Press. ${ }^{14}$ HOBBES, T. (1999) Leviatán: la materia, forma y poder de un Estado eclesiástico y civil. Madrid: Alianza.

${ }^{15}$ ALTHUSSER, L. (2003) Ideología y aparatos ideológicos del Estado. Buenos Aires: Nueva Visión.

${ }^{16}$ CHATTERJEE, P. (2004) The politics of the governed - Reflections on popular politics in most of the world. New York: Columbia University Press.
} 
esta perspectiva, el estado aparece como una gestión emocional que interactúa de manera afectiva con las personas, y de ese modo aparece en su vida.

La literatura de las burocracias callejeras ${ }^{17}$ ya nos ha mostrado cómo esa gestión emocional se visibiliza por medio de personas que, revestidas de competencias de autoridad, llevan la idea del estado a la vida de los beneficiarios de los programas sociales. Pese a ello, concebir el estado como afecto aleja la atención de los mecanismos que le permiten convertirse en la autoridad misma (poder institucional) o en provisiones materiales (ciudadanía social). Es la mera empatía lo que aparece en la vida de las personas ${ }^{18}$. En consecuencia, el estado no debe ser entendido como una ficción que debe ser deconstruida, como lo proponían las aproximaciones anteriores a la antropología del estado ${ }^{19}$, sino como una relación sustantiva. Es una interacción, un intercambio de quejas, reclamos, apelaciones, anhelos que, hechos a partir de registros emocionales, se inscriben en formas jurídicas que median esas relaciones (derechos, privilegios, prerrogativas). El derecho es, entonces, una forma de nombrar la emoción, el afecto. Que el estado sea una emoción es entonces una buena aproximación desde el punto de vista descriptivo.

La etnografía burocrática empezó a dar cuenta de esto cuando subrayó cómo las burocracias callejeras operaban mediante la producción y circulación del miedo, la esperanza y la sospecha, además de recurrir a tácticas de gobernanza como la clasificación, la inscripción y la organización ${ }^{20}$. El estado es un objeto de inversión emocional, un lugar de miedo, paranoia y sospecha mutua, lo cual, por supuesto, es un avance importante para las investigaciones que indagan cómo el estado se hace material o cómo aparece en la vida de las personas. La politización del afecto de espacios particulares o el acto de vincular esas manifestaciones emocionales a símbolos políticos y discursos hacen que el estado se vuelve tangible y cobre una existencia espacial o real. Este modo de aparecer es una forma de gobierno y de la “insustanciabilidad del poder” del mismo estado ${ }^{21}$.

El estado, por tanto, no necesita ser entendido como entidad, limitada, invisible, abstracta; puede ser visto como una caja de resonancia afectiva entre distintas personas y cosas ${ }^{22}$. En las secciones siguientes, de conformidad con este guion, desarrollaré cómo esta aproximación puede

\footnotetext{
${ }^{17}$ HUPE, P., HILL, M. y BUFFAT, A. (2016) Introduction: defining and understanding street-level bureaucracy. In: HUPE, P., HILL, M. y BUFFAT, A. (Ed.) Understanding street-level bureaucracy. Bristol: Policy Press.

${ }^{18}$ REEVES, M. (2011) Fixing the border: On the affective life of the state in southern Kyrgyzstan. Environment and Planning, 29(5), pp. 905-923.

${ }^{19}$ ABRAMS, P. (1988) Notes on the difficulty of studying the state. Journal of Historical Sociology, 1(1), pp. 58-89.

${ }^{20}$ NAVARO-YASHIN, Y. (2009) Affective spaces, melancholic objects: ruination and the production of anthropological knowledge. Journal of the Royal Anthropological Institute, 15(1), pp. 1-18.

${ }^{21}$ TAUSSIG, M. (1992) The nervous system. New York: Routledge.

${ }^{22}$ TAUSSIG, M. (1997) The magic of the State. New York: Routledge.
} 
resultar productiva para analizar los procesos públicos de construcción de ciudadanía de las víctimas de Bellavista, Bojayá. En este contexto, la viñeta etnográfica de la asamblea para decidir la aceptación o no del Cristo Negro me permitirá analizar los procesos emocionales que constituyen los procesos políticos y públicos en el territorio, encargados de mediar las relaciones entre aquellos sujetos que se llaman “víctimas” y aquellos denominados “estado”.

\section{EL ESTADO EMOCIONAL DENTRO DE NOSOTROS: REALIDADES COLOMBIANAS}

Para distensionar el ambiente, el líder del Comité de Víctimas del Dos de Mayo (CVDM) intervino para recordar por qué estos escenarios son claves para fortalecerse a sí mismo y cómo todas las opiniones son válidas. Igualmente, las personas del Centro Nacional de Memoria Histórica recordaron dos cosas: primero, que Bojayá ya no era más Bojayá, era la nación entera dando mensajes de reconciliación. El resultado de esa asamblea, el perdón que pudiera dar la comunidad recibiendo el gesto de las FARC era muy importante para la coyuntura. Segundo, que las opciones no eran solamente dos. No estaban frente a una decisión de recibirlo o rechazarlo. La comunidad podía también usar el escenario para recibir el Cristo como un gesto de reconciliación, pero condicionar la reparación a algunos puntos importantes, como la exhumación e identificación de los muertos, las inversiones en salud, la revisión del sistema de indemnizaciones por fiducias.

El líder del CVDM terminó esa parte de la sesión hablando como miembro de la comunidad, y no como miembro del Comité. Para él, el Cristo debía ser recibido como un símbolo del perdón que pusiera fecha a algunas acciones que debían ser realizadas por las FARC.

El estado es emocional en todas partes. Podría construir un argumento aquí sobre cómo existe el estado emocional en las zonas afectadas por la violencia, lejanas y distantes. Debo admitir que ese fue mi primer impulso, pero la lejanía no es un elemento explicativo cuando hablamos del estado como gestión emocional.

Cuando estoy en un centro de atención distrital especializado (Cade) en Bogotá o en cualquiera de las oficinas de las Empresas Municipales de Cali (Emcali), puedo ver la misma escena: personas descargando su rabia en una ventanilla, haciendo reclamos fuertes por insatisfacciones, presentando quejas por malos servicios. En otras palabras, soy testigo de “altercados burocráticos”. Observo la misma interacción afectiva en los procesos de rendición de cuentas o en una audiencia de aclaración de pliegos en el Fondo Financiero de Proyectos de Desarrollo (Fonade). La existencia del estado como emoción no constituye necesariamente una forma de precarización.

En lugares como Bojayá, percibía intuitivamente las emociones como una manifestación de precariedad. En ese guion, la emoción aparece como una forma subpolítica: ellos y ellas no tienen estado, tienen emociones. Pero ya hemos visto, de la mano de los trabajos de las etnografías del estado, que esta es una forma singular de gestión emocional que se presenta como pública, oficial. 
No es entonces la distancia lo que explica que el estado se convierta en emoción; la emoción, como manifestación pública, no implica por sí misma una forma de pauperización o de precariedad ${ }^{23}$.

Es innegable, por ejemplo, que el Centro Nacional de Memoria Histórica (CNMH) es la presencia del estado más visible en Bojayá. En una entrevista con un líder del CVDM, él mencionó que "ellos (las personas del CNMH) son los locos del estado" (Entrevista 2, Cali, líder del CVDM, 9 de septiembre, 2016). Están ahí y se dedican a cosas “locas”. “Locas” describe en su narrativa un tránsito irregular de las funciones públicas: se preocupan por la construcción de la memoria, por la reparación, por el perdón. Pero, además, están representando al estado en un lugar donde sistemáticamente este no ha hecho presencia.

El CNMH fue creado para reunir y recuperar material relativo a las violaciones que menciona el artículo 147 de la Ley de Víctimas y Restitución de Tierras. Su metodología de acción sin daño hace énfasis en las intervenciones no extractivas del territorio, en la interacción dignificante con las víctimas, en la importancia de los procesos comunitarios que las empoderen. Habla de memoria, habla de duelo, habla de perdón. El Centro desarrolla actividades terapéuticas que buscan fortalecer los tejidos sociales de la comunidad, respetar sus voces, hacer eco de sus resistencias (Nota de campo, salida 5, Bogotá, reunión de Grupos Regionales de Memoria, 21 de octubre, 2016). Sus funcionarios son cuidadosos en determinar qué quiere la comunidad que se cuente y cómo quiere que se haga.

El Centro es una entidad sin mucho presupuesto y “pequeña” en términos de visibilidad en el organigrama de lo público estatal; sin embargo, ha sido especialmente efectivo para instalar la emoción como centro del debate político en la comunidad de Bellavista. Para esta población -y quiero escribir esto sin que mal entiendan mi intención-, hace visible su dolor. La masacre puso a Bojayá en el centro de las discusiones sobre las víctimas civiles del conflicto armado. Es un caso emblemático por el poder de sus hechos y símbolos -un ataque en una parroquia donde murieron, población civil indefensa, niños y niñas-, por lo dolorosos e impresionantes, que se cruza, además, con elementos estructurales de abandono: es Chocó, Atrato medio, población afro e indígena...

Bellavista, lugar donde ocurrió la masacre en el 2002, es distinta a otras poblaciones de Bojayá como consecuencia de dicho ataque. Sus casas son producto de indemnizaciones parciales que dio el gobierno Uribe y son notablemente más cómodas que las viviendas palafíticas de otros lugares de la región. Tiene calles demarcadas, parques, monumentos. Sus habitantes viven, como lo dije al principio, con las necesidades básicas insatisfechas. Pero hay precariedades mayores en las

\footnotetext{
${ }^{23}$ FRASER, N. y GORDON L. (1997) Una genealogía de la “dependencia”. Rastreando una palabra clave del Estado Benefactor en los Estados Unidos. En: FRASER, N. Iustitia Interrupta. Reflexiones críticas desde la posición “postsocialista”. Bogotá: Siglo del Hombre.
} 
comunidades cercanas. Esto es innegable (Nota de campo, salida 1, Bellavista, conmemoración 14 años de la masacre, 29 de abril-3 de mayo, 2016).

La centralidad del evento de violencia y su reconocimiento como víctimas ha llevado a que sean esos elementos los que predominen en los escenarios políticos, en la manera de construir la conciencia del nosotros colectivo, en el modo de imaginarse a ellos mismos (Nota de campo, salida 1). La masacre es un lugar importante de su vida política. Es un evento fundacional, originario ${ }^{24}$. Ante esto, la presencia del estado en forma de centro de memoria ha contribuido al enconamiento de la identidad de víctimas como forma de politización. En consecuencia, las interacciones con el estado están constantemente mediadas por solicitudes relacionadas con la masacre y se inscriben dentro de sus sucesos, sus recuerdos. Esto, además, lo mencionan una y otra vez los representantes de las entidades públicas. Fue muy ilustrativo, por ejemplo, cuando una funcionaria de la Unidad de Víctimas afirmó en una reunión en Bellavista que no era posible construir un hospital, porque las acciones de reparación permitidas por la Ley 1448 los tenían que devolver a la situación anterior en la que estaban: antes no tenían hospital, ahora tampoco (Nota de campo, visita 1).

El énfasis en la existencia emocional del estado ha desplazado las solicitudes propias de la ciudadanía social. Y no quiero decir aquí que pedir agua, salud, educación, no sea emocional. Estoy señalando que politizar a la comunidad en torno a la masacre y su identidad de víctimas precariza sus relaciones de ciudadanía y la pone en lugares marginales de contacto con el estado. En este contexto, lo que hacen el Centro y la Unidad de Víctimas en Bojayá es “regatear” prestaciones públicas duras²5.

$\mathrm{Al}$ principio de este texto caractericé al CNMH como una burocracia "blanda". Uso el adjetivo para enfatizar su marginalidad (está adscrito al DPS), su temporalidad (la Ley 1448 de 2011 le puso como término el año 2021) y su precariedad (tiene un exiguo presupuesto propio) (Entrevista 1, Cali, funcionario de CNMH, 18 de marzo, 2016). En la voz de algunos de sus funcionarios, el Centro gasta parte importante de su tiempo tratando de “articular” competencias públicas para cumplir derechos de las víctimas: se reúne con los ministerios de educación, salud, vivienda. Pese a ello, esas interacciones son fallidas (Nota de campo, salida 3, Bellavista, fiestas patronales, 13-20 de julio, 2016).

\footnotetext{
${ }^{24}$ La nostalgia y el dolor son sentimientos recurrentes en los hitos políticos e históricos que narran los procesos políticos. El duelo, la melancolía y la catástrofe son formas recurrentes con las que contamos nuestra independencia, nuestra unidad como comunidad, nuestra construcción como comunidad política. Ver: CASTILLEJO-CUÉLLAR, A. (2008) De la nostalgia, la violencia y la palabra: tres viñetas etnográficas sobre el recuerdo. Revista Nómadas, 29, pp. 8-19.

${ }^{25}$ CHATTERJEE, P. (2004) The politics of the governed - Reflections on popular politics in most of the world. New York: Columbia University Press.
} 
Los relatos de sus funcionarios y funcionarias dan cuenta de la fragilidad de su relación con las burocracias duras. Constantemente aluden al riesgo de que el Centro se acabe por presiones políticas. Ante esta situación, perciben a las universidades como una institucionalidad paralela en la que pueden "instalar” el conocimiento que han adquirido sobre construcción de memoria histórica (Nota de campo, salida 5, Bogotá, reunión de Grupos Regionales de Memoria, octubre 21, 2016). Sus relatos también refieren la ambivalencia de su identidad: pueden considerarse funcionarios públicos o investigadores independientes. Por ejemplo, para hacer seguimiento a las recomendaciones que el CNMH había hecho en el informe “Bojayá: la guerra sin límites”, el equipo jurídico del proyecto necesitaba identificar las instituciones públicas a las que el CNMH hacía referencia. Muchas de las recomendaciones estaban vinculadas a instituciones inexistentes y el seguimiento no pudo realizarse en esos casos. Cuando indagué en las instituciones públicas por estas referencias, me encontré con esta respuesta: “ellos no tienen ni idea de donde están parados [...]. Es que eso es más como un centro de investigación, no es formalmente una institución del estado” (Nota de campo, salida 5, Bogotá, reunión de Grupos Regionales de Memoria, 21 de octubre, 2016).

Una situación como esta resulta más llamativa cuando, en las oficinas de la Unidad de Víctimas de Quibdó, se refieren a los miembros del Comité de Víctimas de Bojayá (el mismo CVDM) como representantes “oficiales” de lo que sucede en el municipio (Notas de campo, salida 2, Quibdó, reunión con unidad de víctimas y CVDM, 2-3 de junio, 2016). Mientras son identificados como voceros de la comunidad, representan un estado que los traiciona; de hecho, los mismos funcionarios en los territorios los reconocen como "mediadores oficiales” (Notas de campo, salida 2).

Los anteriores ejemplos indican que el estado en Bojayá es una cadena de eslabones falsos: el CNMH es una de las instituciones presentes, pero ella misma tiene conexiones frágiles con las entidades públicas y los enlaces públicos son personas que, pese a desarrollar una labor comunitaria visible e importante, no tienen ningún vínculo formal con el estado: no responden a un contrato de prestación de servicios, a un nombramiento oficial o a un convenio de colaboración.

Por otra parte, el rol de los miembros del Comité de Víctimas de Bojayá y otras organizaciones comunitarias, como el Consejo Comunitario Mayor de la Asociación Campesina Integral del Atrato (Cocomacia), es singular para dar cuenta de la precariedad de las presencias estatales en Bellavista. Aunque no son abogados ni tienen ninguna experiencia dentro de la burocracia oficial, estas personas no solo han sido las cabezas visibles del proceso de lucha posterior a la masacre: han liderado la gestión documental, el envío de solicitudes oficiales, la mediación con organismos internacionales como la ONU, la orientación de asambleas comunitarias constantes y la utilización de una jerga especializada en procesos y acciones que los posicione como víctimas del 
conflicto frente al estado. En ellos, el estado se condensa. Estos hombres y mujeres son archivos ambulantes, recuerdan con claridad fechas e interacciones con el estado; sus memorias personales son las memorias oficiales del conflicto (Entrevista 2, Cali, líder del CVDM, 9 de septiembre, 2016).

La acción cotidiana de estos líderes está altamente burocratizada. Sus formas de movilización y expresión emulan al estado, que los abandona, pero construyen la sensación de su falsa presencia ${ }^{26}$. Esa existencia del estado en performances burocráticos vacíos de significado o expresiones de vínculos formales con el estado se ha señalado como una de las formas de precarización de lo estatal propia de los contextos neoliberales en países como Colombia ${ }^{27}$.

Pese a esas sensaciones, los representantes del CVDM se han negado de manera sistemática a constituir personas jurídicas u otras figuras legales que lleven a la representación formal de la comunidad. Han sostenido esta posición, aunque la Fiscalía ha desestimado varias veces su liderazgo o mediación hasta tanto no obtengan una personería jurídica. Esto es paradójico puesto que no solo los funcionarios del estado reconocen el liderazgo y la legitimidad de los miembros del CVDM. La comunidad frecuentemente recuerda y ratifica su liderazgo, su solidaridad, su voz. Procesos nacionales como internacionales aceptan la visibilidad de su gestión ${ }^{28}$.

Según el líder del CVDM entrevistado, uno de los argumentos para negarse a constituir una figura jurídica de representación es la responsabilidad del estado. Para él, una personería jurídica daría a uno de los miembros de la comunidad la responsabilidad por las víctimas, cuando esta le corresponde absolutamente al estado (Entrevista 2, Cali, líder del CVDM, 9 de septiembre, 2016). Esta resistencia al uso de las formas jurídicas es, en algún sentido, una resistencia frente al estado. Es una queja indirecta que pone de presente ausencias sistemáticas de la presencia estatalizada y, sobre todo, reclama una responsabilidad exclusiva por las víctimas de la masacre. Esto implica que, pese a representar de manera “simbólica” al estado en algunos escenarios, los líderes y lideresas comunitarias construyen una frontera discursiva que los separa de él: “son ellos, y no nosotros”, los responsables de las víctimas.

Ahora bien, ser víctima y visible es un proceso complejo. Da miedo, dolor. La doble condición encierra en el drama, agobia (Entrevista 2, Cali, líder del CVDM, 9 de septiembre, 2016). Sin embargo, este líder reconoce que esta identidad es la única que le ha permitido su contacto con

\footnotetext{
${ }^{26}$ Su presencia es, al menos, precaria e inestable. Ellos logran la presencia “transitoria” del estado por medio de las respuestas a los derechos de petición o de visitas también transitorias de funcionarios de las burocracias duras.

${ }^{27}$ CHAVES, M. y MONTENEGRO, M. (2015) Usos y sentidos contemporáneos de lo público. Revista Colombiana de Antropología, 51, pp. 7-21.

${ }^{28}$ RIAÑO, P. y BAINES, E. (2012) Cuando el archivo está en el testigo: documentación en escenarios de inseguridad crónica. Análisis político, 4, pp. 49-70.
} 
entidades públicas, el reconocimiento de su pueblo y la visibilidad de su territorio. "Por el dolor existen”, dice él (Entrevista 3, Cali, líder del CVDM, noviembre 16, 2016). Ser víctima concentra, de manera contradictoria para estas personas, todas sus desgracias pasadas, pero al mismo tiempo, la dignidad del reconocimiento presente y la esperanza de una mejora en el futuro.

La existencia del estado en Bellavista habla de esta clase de dramas. Lo público se desvanece en figuras que, pese a tener un rol densamente público, no son estatales. Estas continuas tensiones se recogen en características como la dispersión de lo público, la saturación de la presencia ocasional, la fragilidad de los lazos y la eficacia de los discursos que pronuncian los funcionarios públicos que visitan Bellavista. En la siguiente sección explicaré esta caracterización.

\section{EL ESTADO DEL RÍO: DISPERSIÓN, SATURACIÓN, FRAGILIDAD Y EFICACIA EN LA EXPERIENCIA ESTATAL DE BELLAVISTA}

Salimos a almorzar. Durante el almuerzo, los funcionarios del Centro Nacional de Memoria Histórica $(\mathrm{CNMH})$ reconocieron lo complejo de la situación. Mencionaron lo injusto que es poner a la comunidad en situaciones tan difíciles como esta y cuestionaron los actos de las FARC. ¿Cómo se les ocurrió la idea del Cristo? ¿Por qué justo un cristo? Era realmente una situación bien difícil en la que estábamos.

Llegando de almorzar los ánimos eran distintos. La comida había logrado, una vez más, construir en comunidad lo que la deliberación no pudo. Después del receso, se evaluaron las propuestas de aceptar el Cristo como un gesto de reconciliación y perdón, y enviarlo al Museo de Memoria en Bogotá (lugar al que quedará reducido el CNMH en el 2021). Se descartó la posibilidad de recibirlo sin condiciones o que se entregara a una comunidad distinta a la de Bellavista; finalmente, se acordó recibir el Cristo como un gesto de reparación y se discutieron los puntos que se propondrían a las FARC como claves de la reparación y que permitirían condicionar la aceptación por parte de la comunidad. El encargado de recibir el Cristo sería el Comité de Víctimas del Dos de Mayo.

Al final de esta sesión, un anciano mencionó que eso era como estar escribiendo en el aire, antes de que se firmaran los acuerdos. "No tenemos nada, la paz no está lista y, por lo tanto, la seguridad de la comunidad tampoco existe”. Por esa razón, la reunión terminó con la invitación a firmar por el sí y la filmación de un video en el que los líderes y lideresas de las comunidades se dirigen a los centros urbanos, recordándoles que ellos, como campesinos y campesinas, necesitan la paz para poder trabajar y vivir tranquilos.

El análisis de las viñetas etnográficas seleccionadas sugiere que la ciudadanía precaria a la que me refería en el principio del texto -y que alude a la forma de ciudadanía creada por la Ley $1448^{29}$ - tiene cuatro características fundamentales en este contexto: fragmentación, saturación, fragilidad y eficacia. La dispersión se refiere a la idea del estado como algo aparentemente

\footnotetext{
${ }^{29}$ Este tipo de ciudadanía se remonta por lo menos a la creación del “desplazado” de la Ley 387 de 1997 y se consolida con esta Ley 1448 de 2011. El texto del profesor Esteban Restrepo (2010) es iluminador en este sentido.
} 
homogéneo. Es fácil reconocerla en esos territorios: las competencias de las entidades son difusas y débiles, pero más allá de esto, están dispersas y desagregadas. Las oficinas públicas (de la Unidad de Víctimas, por ejemplo) no se encuentran en centros administrativos condensados (como sucede en algunas ciudades de acuerdo con principios de planeación urbana), sino en zonas periféricas no conectadas con los otros centros administrativos (alcaldías, estaciones de policía).

Adicionalmente, el estado está atomizado en figuras ambiguas que emulan su presencia sin representar su existencia: los miembros del CVDM, los líderes y lideresas comunitarias, las mujeres que cocinan para la comunidad en las asambleas, los funcionarios del CNMH con contratos precarios y presencias efímeras. Esa dispersión y opacidad de lo estatal es propia de la manera en la que el estado constituye su poder ${ }^{30}$. El caos, el desorden y la inteligibilidad de sus estructuras y lenguajes afianzan su autoridad y ejercen su disciplina ${ }^{31}$. La unidad jurídica, esa que representa la Ley 1448, que nombra a las víctimas como sujetos de especial protección del estado y crea una estructura institucional para su asistencia, es la forma de coherencia en la que el estado narra su existencia; sin embargo, esa coherencia y unidad no se experimenta en la vida cotidiana de los habitantes de Bellavista.

La saturación es el antónimo de la dispersión. Mientras yo puedo identificar la dispersión del estado en Bojayá, sus habitantes solo perciben la densidad de su presencia. Se sienten sofocados con reuniones constantes, se ven expuestos de manera frecuente a un vocabulario técnico tedioso y paralizante, son acosados por presencias e interpelaciones inusuales en su territorio. El estado para ellos es saturación. Sienten su presencia en los soldados intimidantes en el parque, en sus armas, en sus voces. Se reconoce robusto en los discursos sofisticados de funcionarios ajenos, en la sensación de estar siendo observados, en la zozobra derivada de visitas constantes de invitados desconocidos.

La fragilidad es contradictoria cuando hablamos del estado saturado. ¿Cómo puede el estado, al mismo tiempo, estar saturado y ser frágil en estos territorios? Ya hablé de la precariedad de las presencias estatales en el Atrato medio. Estas se derivan de la suavidad de las burocracias blandas y la contundencia de las presencias duras. El estado está en las armas de los militares del parque, por supuesto, pero se escapa en los papeles de las asambleas del CNMH o en las visitas de la Unidad de Víctimas. Se vuelve frágil cuando lo que llega es empatía y no hospitales; escucha y no escuelas; condescendencia y no resultados (Entrevista 2, Cali, líder del CVDM, 9 de septiembre, 2016). El

\footnotetext{
${ }^{30}$ LEAL, A. (2006) Burocracia, justicia y pluralismo jurídico. Una exploración de los espacios del poder en Oaxaca. Alteridades, 16(31), pp. 39-48.

${ }^{31}$ GUPTA, A. (2012) Red tape. Bureaucracy, structural violence and poverty in India. Durham, NC: Duke University Press.
} 
estado se está convirtiendo aquí en una terapia, en una acción afectiva, siendo la preocupación por las emociones la única manera de evidenciar su existencia en estos territorios. En ese sentido, el “estado empático” sí es una forma de precarización de la ciudadanía en estos territorios.

Finalmente, el estado empático y la ciudadanía precaria son eficaces. Esta eficacia se deriva de la sensación fundacional de la operación del estado liberal desarrollista ${ }^{32}$. Es el estado que no está, no quiere estar, pero debe lidiar con la expectativa de la presencia. Entonces, aparece en estas formas: trabajando el duelo, escuchando el dolor, reconstruyendo la memoria. El CNMH nombra a los líderes y lideresas comunitarias que participan en sus actividades como “gestores de memoria”. Y la paradoja es que, al mismo tiempo, estas presencias cumplen las promesas de la existencia mientras disimulan ausencias estructurales, disipan reclamos legales y enredan reivindicaciones políticas. Esta es la gestión emocional de la ciudadanía precaria.

Dispersión, saturación, fragilidad y eficacia pueden reconocerse en las viñetas etnográficas analizadas. El escenario mismo nos habla de la centralidad de los intercambios emocionales como representaciones de lo público en territorios como el de Bellavista. La manera en la que las personas enuncian su inconformidad, la disposición del espacio, el tono que usan las personas para desplegar sus opiniones muestran cuán acostumbradas están a hablar de esto: perdón, rencor, llanto, dolor. Todas estas son expresiones de duelo que reemplazan el ejercicio de la ciudadanía.

El escenario también revela cómo el estado aparece en estos espacios. Llega por el río, se aleja por él. Se muestra preocupado, como los funcionarios del CNMH; inconforme, indignado. Ellos escuchan a la comunidad, la atienden, la conocen. Pueden reconocer sus voces, sus nombres, sus casas. Su rol revierte la jaula de hierro weberiana: son cercanos, conscientes, compasivos $^{33}$. Hablan del perdón, de la importancia de su dignidad, de su voz como víctimas. Son garantes de la "acción sin daño”. Son personas, no estructuras. Son individuos, no servicios. Y mientras eso pasa, el olvido persiste. No llega la luz, el agua. No llega la paz.

Los habitantes de Bojayá tienen clara esa contradicción. Para ellos, no hay tal "reparación integral” de la que habla la Ley 1448 de 2011 y sobre la que insisten con vehemencia los funcionarios del CNMH (Nota de campo, salida 5, Bogotá, reunión de Grupos Regionales de Memoria, 21 de octubre, 2016). La reparación es simbólica y material. Existe una división clara, y es evidente que la segunda no ha llegado. Por eso, quienes participan de la audiencia se refieren a sus lesiones, a los

\footnotetext{
${ }^{32}$ ESLAVA, L. (2014) 'I feel like a dog with the tail between its legs': on the limits of protest and urban law in our decentralized world. Recuperado de <https://goo.gl/y0n5rj>. De próxima publicación en Human rights beyond the law. Oxford, NY: Oxford University Press.

${ }^{33}$ LÓPEZ, D. (2007) El sueño weberiano: Claves para una comprensión constitucional de la estructura del Estado Colombiano. Revista de Derecho Público de la Universidad de los Andes, 19.
} 
hospitales, a las condiciones de sus viviendas, cuando han sido invitados para hablar del perdón y la reconciliación. Del perdón de ellos que era en ese momento el perdón de Colombia entera. De la Colombia del estado saturado que les pedía a ellos un gesto de perdón. Un gesto de reconciliación...

Pero mientras los enunciados emocionales capturan la escena, los escenarios de la ciudadanía se precarizan. No existe una ciudadanía social en cuanto garantía material para el ejercicio de los derechos civiles y políticos. No existen ni siquiera los canales físicos para que esas reclamaciones puedan darse, porque los funcionarios que los escuchan no son competentes para solucionarlas. Y que no sean competentes les enseña la lección de la que Chatterjee nos hablaba: no son ciudadanos y ciudadanas completos.

\section{EPÍLOGO}

El Cristo estaba en el piso de una antigua iglesia. [...] Me impresionó, primero, su tamaño. Luego, debo decir, me frustró su imagen. No era tan fino como me lo imaginaba. Estaba aún por terminar, la pintura por hacer y estaba aún tosco por la falta de lija. Sus piernas eran más gruesas de lo normal; sus caderas, en cambio, estrechas. Su cara, polémica. Tenía rasgos afro con varias rastas colgando como pelo.

[...] Para Enrique Angulo, el artista cubano que había creado la obra, la escultura incluía tres símbolos de resistencia, por lo que le costaba creer que la comunidad la rechazara. Los pies, por ejemplo, se resistían a ser clavados. Eran unos pies en lucha. El segundo símbolo de resistencia era el color. Era el primer cristo que originalmente tenía ese color: los dos existentes eran de ese tono como resultado de incendios. Hacer un cristo negro parecía un acto de rebeldía para un ateo como él. Finalmente, el último símbolo de resistencia era la herida en el dorso. Su visibilidad era mucho más profunda, su sangre más visible, más marcada. Era, sin lugar a dudas, una manera de hablar sobre la masacre y su magnitud.

Meses después, cuando ya se había realizado el plebiscito y el presidente Santos había recibido el Nobel de la Paz, yo estaba en Londres en uno de los reconocimientos al presidente. En el aeropuerto, un inglés que trabaja para Heathrow me dijo: “qué valiente es su país, qué emoción esto que vimos en estos días. Está lleno de personas muy alegres. Me sorprende cómo vinieron aquí y sacaron las banderas, después de tanto dolor” (Nota de campo, salida 6, Londres, reconocimiento al Presidente de la República de Colombia como Nobel de Paz, 6-12 de noviembre, 2016). Cruzando el Atlántico, se producía otro ejercicio de construcción simbólica y emocional de lo político. De algún modo, ser ciudadanos en estas fronteras (y quizás en todas) tiene que ver con gestionar ese tipo de emociones: perdón, reconciliación, pertenencia. Pero el hallazgo aquí ha sido que ese tipo de gestiones capturan no solo las acciones macro del estado. Las emociones se esconden y filtran donde nos han enseñado que el estado es solo técnica (leyes, normas, imparcialidad). 
Ahí, en Londres, se había realizado una asamblea de perdón. Actos de reconocimiento, de dignificación, de paz. Actos que simbolizan la esperanza. Yo viajé a Bogotá contenta. Al llegar, en la madrugada, un niño hambriento me recordó las distancias entre los dolores cuando me pidió a las 4 a.m. dinero para comer. El estado empático y la ciudadanía precaria hablan de estas contradicciones, de la existencia limitada de los símbolos, de la fragilidad de los procesos emocionales cuando se trata de construir una ciudadanía política. De alguna manera, los conflictos sociales hablan de precariedades materiales: hambre, miseria, pobreza.

En la etapa del post-acuerdo en Colombia, que busca implementar los acuerdos de la Habana que acabaron con más de cincuenta años de conflicto político entre la guerrilla de las FARC EP y el estado colombiano, analizar los conflictos cotidianos y el impacto en la vida de las personas debe estar en centro de la agenda investigativa. El énfasis en “el conflicto”, como centro de la vida política, debe ceder espacio al estudio de "los conflictos”, con minúscula, en donde el género, la raza-etnia, la clase y las emociones de las personas ocupan un lugar protagónico, que había estado oculto en las prioridades políticas y académicas. Las preocupaciones de las víctimas y cómo usan el derecho para articular sus deseos y tramitar sus inconformidades, muestra micro-conflictos que, pese a parecer mundanos, sub-políticos y exiguos, deshacen el tejido social colombiano mostrando otras dimensiones de la violencia. Esperamos que esta investigación sea útil para avanzar en el análisis de ciudadanías agonizantes, como las de las víctimas de Bojayá.

\section{REFERENCIAS}

ABRAMS, P. (1988) Notes on the difficulty of studying the state. Journal of Historical Sociology, 1(1), pp. 58-89.

ALTHUSSER, L. (2003) Ideología y aparatos ideológicos del Estado. Buenos Aires: Nueva Visión.

ALVIAR GARCÍA, H. y JARAMILLO SIERRA, I. C. (2012) Feminismo y crítica jurídica: el análisis distributivo como alternativa crítica al legalismo liberal. Bogotá: Siglo del HombreUniandes.

CASTILLEJO-CUÉLLAR, A. (2008) De la nostalgia, la violencia y la palabra: tres viñetas etnográficas sobre el recuerdo. Revista Nómadas, 29, pp. 8-19.

CENTRO NACIONAL DE MEMORIA HISTÓRICA - CNMH (2010) Bojayá: La guerra sin límites. Bogotá: Taurus.

CHATTERJEE, P. (2004) The politics of the governed - Reflections on popular politics in most of the world. New York: Columbia University Press. 
CHAVES, M. y MONTENEGRO, M. (2015) Usos y sentidos contemporáneos de lo público. Revista Colombiana de Antropología, 51, pp. 7-21.

ESLAVA, L. (2014) 'I feel like a dog with the tail between its legs': on the limits of protest and urban law in our decentralized world. Recuperado de <https://goo.gl/y0n5rj>. De próxima publicación en Human rights beyond the law. Oxford, NY: Oxford University Press.

ESPING-ANDERSEN, G. (1999) Social foundations of postindustrial economies. Oxford, NY: Oxford University Press.

FRASER, N. y GORDON L. (1997) Una genealogía de la “dependencia”. Rastreando una palabra clave del Estado Benefactor en los Estados Unidos. En: FRASER, N. Iustitia Interrupta. Reflexiones críticas desde la posición “postsocialista”. Bogotá: Siglo del Hombre.

GUPTA, A. (2012) Red tape. Bureaucracy, structural violence and poverty in India. Durham, NC: Duke University Press.

HOBBES, T. (1999) Leviatán: la materia, forma y poder de un Estado eclesiástico y civil. Madrid: Alianza.

HUPE, P., HILL, M. y BUFFAT, A. (2016) Introduction: defining and understanding street-level bureaucracy. In: HUPE, P., HILL, M. y BUFFAT, A. (Ed.) Understanding street-level bureaucracy. Bristol: Policy Press.

LASZCZKOWSKI, M. y REEVES, M. (2015) Affective states - entanglements, suspensions, suspicions. Social Analysis, 59(4), pp. 1-14.

LEAL, A. (2006) Burocracia, justicia y pluralismo jurídico. Una exploración de los espacios del poder en Oaxaca. Alteridades, 16(31), pp. 39-48.

LEMAITRE RIPOLL, J. (2013) Diálogo sin debate: la participación en los decretos de la Ley de Víctimas. Revista de Derecho Público, 31, pp. 5-37.

LÓPEZ, D. (2007) El sueño weberiano: Claves para una comprensión constitucional de la estructura del Estado Colombiano. Revista de Derecho Público de la Universidad de los Andes, 19.

MARSHALL, T. H. (1992) Citizenship and Social Class. London: Pluto Press.

NAVARO-YASHIN, Y. (2009) Affective spaces, melancholic objects: ruination and the production of anthropological knowledge. Journal of the Royal Anthropological Institute, 15(1), pp. 1-18.

NAVARO-YASHIN, Y. (2012) The make-believe space: affective geography in a postwar polity. Durham, NC: Duke University Press.

RECALDE, G. “En lo que esté a mi alcance les ayudo”. Los funcionarios de base y las víctimas en el proceso de declaración para la inscripción en el Registro Único de Víctimas del conflicto armado. En: JARAMILLO, I. C. y BUCHELY, L. (Coord.). Etnografías burocráticas. Bogotá: Uniandes (en proceso de edición). 
REEVES, M. (2011) Fixing the border: On the affective life of the state in southern Kyrgyzstan. Environment and Planning, 29(5), pp. 905-923.

RESTREPO, E. (2010) Cómo garantizar justica a los desplazados. El desplazado como paria. La garantía de los derechos a la verdad, la justicia y la reparación de las víctimas del delito de desplazamiento forzado en Colombia. En: Más Allá Del Desplazamiento. Bogotá: Editorial Uniandes.

RIAÑO, P. y BAINES, E. (2012) Cuando el archivo está en el testigo: documentación en escenarios de inseguridad crónica. Análisis político, 4, pp. 49-70.

TAUSSIG, M. (1992) The nervous system. New York: Routledge.

TAUSSIG, M. (1997) The magic of the State. New York: Routledge.

VERGARA-FIGUEROA, A. (2016) ¿Cómo puede Bojayá perdonar? Recuperado de $<$ https://goo.gl/Dc1tkI> el 6 de octubre de 2016.

Lina Buchely

Doctora en Derecho de la Universidad de los Andes. Magister en Derecho e Instituciones Legales en la Universidad de Wisconsin - Madison. Politóloga, Abogada y Magister en Derecho de la Universidad de los Andes. Ocho años de experiencia en docencia en pregrado y posgrados dentro del área de teoría del Derecho y derecho constitucional. Actualmente es profesora asistente de la Universidad Icesi y Directora del Programa de Derecho. Tiene publicaciones relacionadas con temas de Filosofía del Derecho, Estudios de Género y Política Social. Actualmente es la Directora del Programa de Derecho de la Universidad Icesi en Cali - Colombia.E-mail: lfbuchely@icesi.edu.co 